\title{
Imre Friedmann
}

$\mathbf{T}$ HE FIELD OF ASTROBIOlOgy has lost a founding member and an outstanding scientist in Imre Friedmann, who died peacefully on June 11, 2007 after a difficult heart surgery. Imre was born in Budapest, Hungary, on December 20, 1921. From an early age, he was determined to be a biologist. Imre had a wide-ranging career in studies of marine and terrestrial algae as well as microscopy. His last active project involved state-of-theart electron microscopy of martian meteorites, searching for possible biogenic magnetite chains. This work goes on.

Imre is best known for his discovery of the cryptoendolithic microbial ecosystem in the sandstone rocks of the dry valleys of Antarctica. He spent the better part of 20 years characterizing this unusual ecosystem and studying comparative systems in the Arctic, the Negev, and other deserts. It was on one of these Antarctic expeditions that I began working with Imre. I was a young graduate student in physics, and the experience changed my life. I learned from Imre the utility and excitement of interdisciplinary research and the importance of field work. My fondest memories of time spent with Imre were the many times in the field at the end of a busy day when the discussion would range from the microbial to the astronomical. I was learning "astrobiology" from him decades before NASA coined the term. It was these discussions that generated my interest in the field. I have followed that lead since.

Imre was active to the last. We did major field trips to the Mojave Desert and the Dead Sea in 2006. He was as active, engaged, and insightful as ever.

Imre spoke his mind, politely but clearly. I recall the several times that I was the recipient of his candor. Imre was famous among his students and junior colleagues for asking: "What is the question that you are trying to answer?" I still quote him.

Imre was another brilliant Hungarian scientist illustrating that the often-remarked group of outstanding Hungarian physicists who came to the United States at the time of World War II had counterparts in biology. As a Jew in Hungary

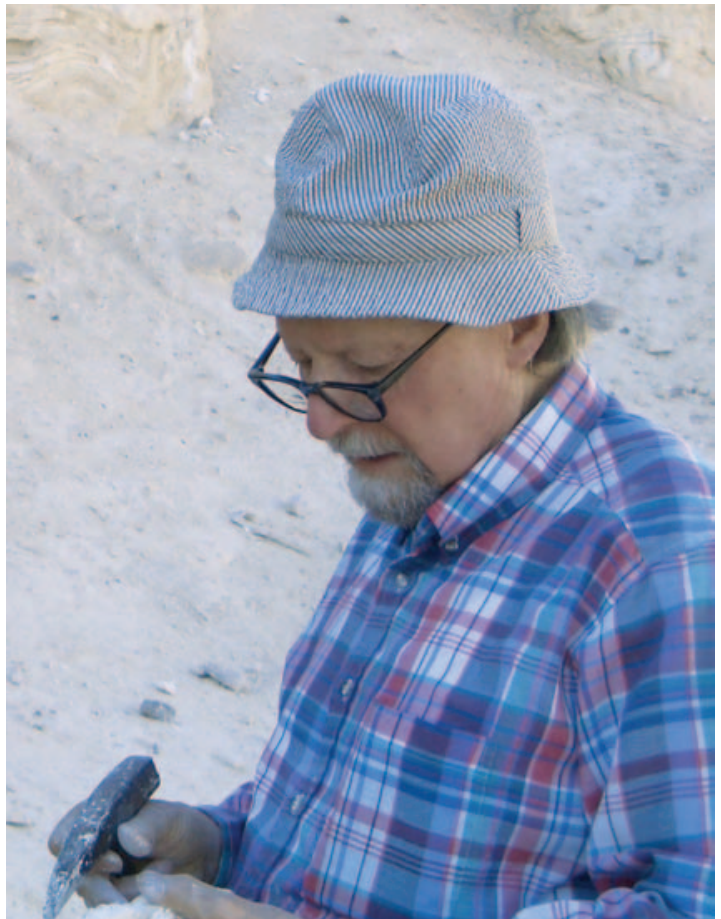

Imre Friedmann at the Dead Sea, June 2006.

during the war, Imre survived the Nazi labor camps, fled the Nazis, then fled the Communists and completed his education in Vienna. He then went to Israel before coming to the United States, which was his home for the rest of his life. His life is a lesson in dedication to science and an example that cultures that encourage freedom will attract the best and the brightest. Imre's memory would be well served if we redoubled our efforts to ensure that we do respect the freedoms we espouse both in science and in our culture.

Any tribute to Imre Friedmann must end with the observation that he loved good food and fine wine. He was also an outstanding cook. In our Antarctic field camps he would prepare delicious meals. I will miss him in many ways.

-Chris McKay

Building 245, Room 212

NASA Ames M.S. 245-3

Moffett Field, CA 94035 